\title{
A modified technique of retrograde intubation dacryocystorhinostomy for proximal canalicular obstruction
}

This article was published in the following Dove Press journal:

Clinical Ophthalmology

18 November 2009

Number of times this article has been viewed

\section{Nikolaos Trakos \\ Emmanouil Mavrikakis \\ Kostas G Boboridis \\ Marselos Ralidis \\ George Dimitriadis \\ loannis Mavrikakis}

Oculoplastic Service, Metropolitan

Hospital, Athens, Greece
Correspondence: loannis Mavrikakis

Solonos 18, Kolonaki, 106 73,

Athens, Greece

Tel +302103619006

Fax +302103619339

Email jmavrikakis@yahoo.com
Purpose: To describe a modification of the retrograde intubation dacryocystorhinostomy (DCR) in patients with proximal canalicular obstruction.

Materials and methods: Interventional case report of a 43 -year-old female with a nine-month history of left epiphora following a road traffic accident involving the proximal lower canaliculus. An external DCR approach was performed. Following the creation of a lower canalicular pseudopunctum, the O'Donoghue silicone stent was introduced through the common ostium, out through the pseudopunctum of the lower canaliculus, and returned through the punctum of the normal upper canaliculus down through the common ostium into the nose.

Results: The patient experienced complete resolution of symptoms and on her last follow-up, two years later, her lower canaliculus was patent to syringing.

Conclusion: This modification of the retrograde intubation DCR is an effective technique which decreases the intraoperative time needed to insert the tubes and minimises further trauma to the newly created punctal area.

Keywords: retrograde dacryocystorhinostomy, proximal canalicular obstruction, midcanalicular obstruction, conjuctivodacryocystorhinostomy

Canalicular obstruction can be one of the most difficult lacrimal conditions to treat. Conjuctivodacryocystorhinostomy (CDCR) with a Lester Jones bypass tube is the standard treatment in these situations. ${ }^{1}$ Although a high rate of anatomic success can be achieved with this procedure, many studies over the last 20 years have reported a relatively high rate of complications and poor patient satisfaction. ${ }^{2,3}$ Because of this, alternative techniques have emerged. ${ }^{4}$

One of these techniques, presented by Wearne and colleagues, ${ }^{5}$ is the dacryocystorhinostomy (DCR) with retrograde intubation for the treatment of patients with proximal and midcanalicular obstruction. In this paper we present an evolution of this technique which decreases the intraoperative time needed to insert the tubes and minimises further trauma to the newly created punctal area.

\section{Case report}

A 43-year-old female presented to our unit with a nine-month history of intense continuous epiphora at the level of the medial canthus after a road traffic accident with injury to the left lower eyelid involving the lower canaliculus. Primary repair to the laceration of the eyelid had been performed in another unit with no canalicular repair. Diagnostic syringing was performed which revealed proximal lower canalicular 
obstruction $3 \mathrm{~mm}$ from the punctum. The upper canaliculus was patent. The rest of the ophthalmic examination was normal.

\section{Surgical technique}

We performed a standard external DCR. Once the lacrimal sac was opened, the common ostium was visualised. We inserted a blunt-tipped ' $\mathrm{O}$ ' gauge probe, the distal $1.5 \mathrm{~cm}$ of which was at right angle, retrogradely into the common internal opening and passed in the direction of the lower canalicular system. The tip of the probe was palpable near the eyelid margin, distally to the obstruction, and a scalpel was used to cut down onto the probe tip and thereby create a pseudopunctum (Figure 1). O'Donoghue silicone intubation was performed, the stent being introduced through the common ostium, out through the pseudopuncum of the lower canaliculus and returned through the punctum of the normal upper canaliculus down through the common ostium into the nose (Figure 2). The DCR was then completed in the usual way.

The silicone tubes were removed two months postoperatively and on her last follow-up, two years later, the patient was symptom free with a patent lower canaliculus on syringing.

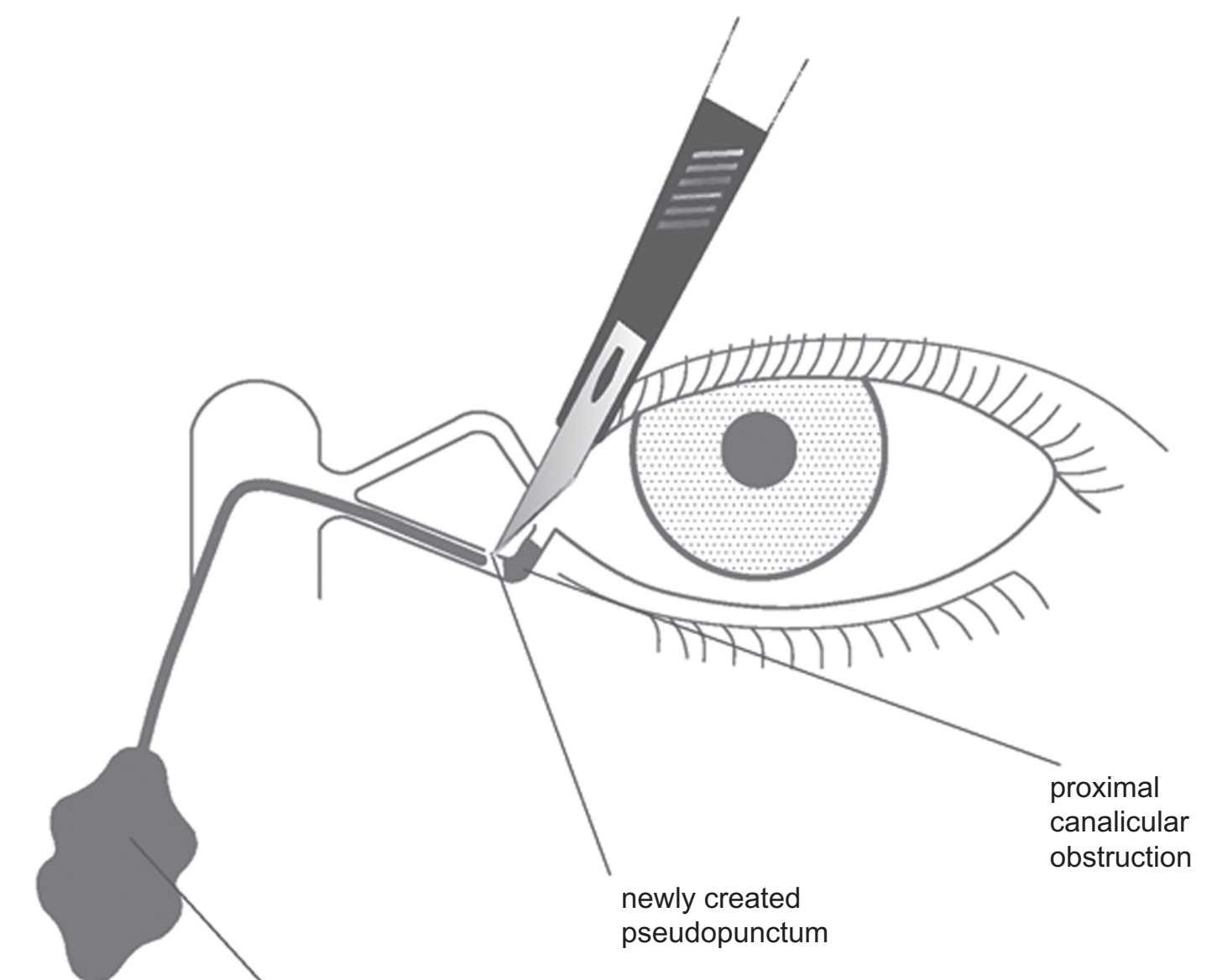

Figure I Diagrammatic representation of the modified retrograde dacryocystorhinostomy technique. A blunt-tipped ' $O$ ' gauge probe, the distal $1.5 \mathrm{~cm}$ of which is at right angle, is inserted retrogradely into the common internal opening and passed in the direction of the lower canalicular system. Note the scalpel which is used to cut down onto the probe tip and create a pseudopunctum. 


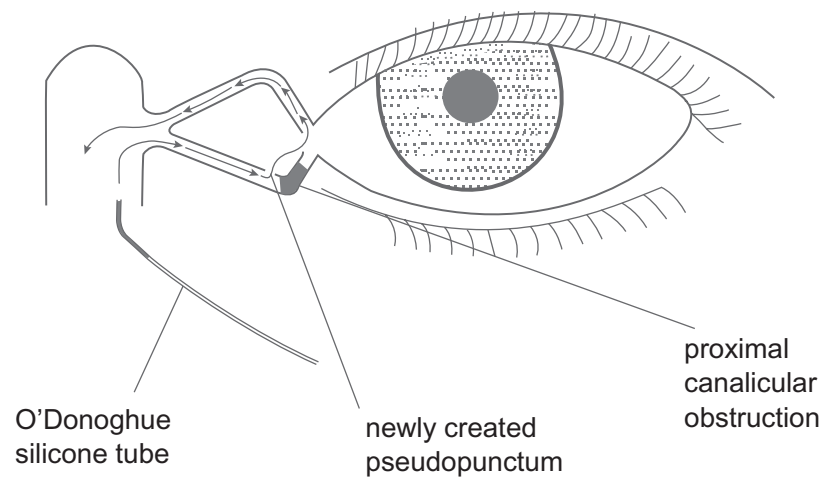

Figure 2 Diagrammatic representation of the modified retrograde dacryocystorhinostomy technique. O'Donoghue silicone intubation is performed, the stent being introduced through the common ostium, out through the pseudopuncum of the lower canaliculus and returned through the punctum of the normal upper canaliculus down through the common ostium into the nose.

\section{Discussion}

Herein we describe a modification of the retrograde intubation DCR technique presented by Wearne and colleagues. ${ }^{5}$ Their procedure is a refinement of the technique originally described by Jones. ${ }^{6}$ The key elements of this procedure are DCR, retrograde probing of the canalicular system, creation of a pseudopunctum, and silicone intubation. We present a further modification of this technique which is based on a different way of inserting the silicone tubes.

Our understanding of the process described by Wearne and colleagues ${ }^{5}$ in cases of proximal and midcanalicular obstruction, where there is one patent canaliculus, is that the stent is first passed through the common ostium into the patent canaliculus out from the punctum and then is introduced through the newly created "pseudopunctum" of the abnormal canaliculus and returned into the nose.

Our technique differs to the one described by Wearne and colleagues ${ }^{5}$ in that the stent is passed from the normal common internal opening out through the abnormal newly created pseudopunctum and then through the normal patent canaliculus into the nose. With this modified technique we minimize the intraoperative time needed to insert the tubes as we go from healthy to traumatised tissues, making the technique easier. We also minimize further trauma to the newly created punctal area which might be created when trying to locate the pseudopunctum using anterograde insertion of the stent. As a result there is a probable increase of the success rate.

In cases where both canaliculi are obstructed, we advocate introducing the stent through the common internal opening into either canaliculus and then out from one pseudopunctum into the other before returning into the nose (Figure 3), rather than introducing the stent in both

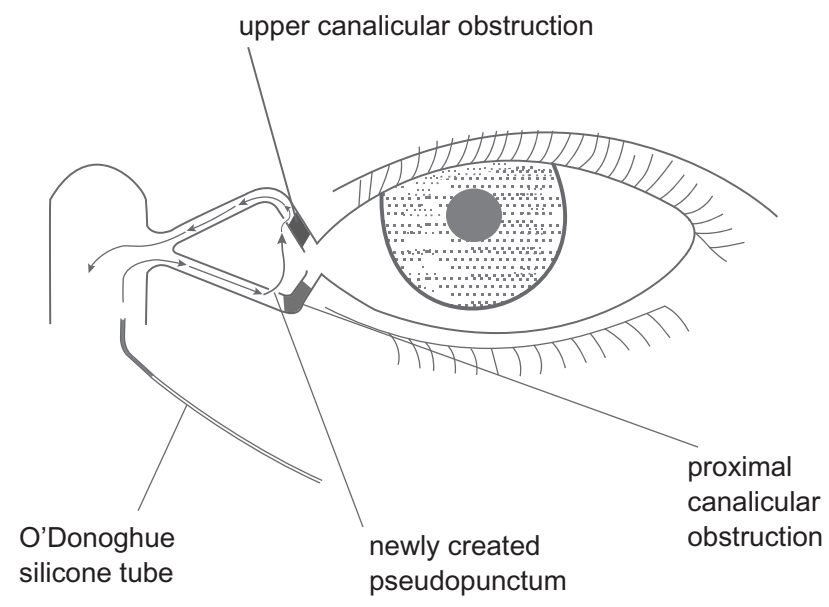

Figure 3 Diagrammatic representation of the modified retrograde dacryocystorhinostomy technique. In cases where both canaliculi are obstructed, we advocate introducing the stent through the common internal opening into either canaliculus (herein lower canaliculus) and then out from one pseudopunctum into the other before returning into the nose.

pseudopuncti in an anterograde fashion. In this situation at least we have the opportunity to introduce one of the stents from one normal to an abnormal anatomic site, rather than the other way around for both canaliculi, thus reducing once again the operating time and trauma.

To conclude we believe that this modification of the retrograde intubation DCR is an effective technique which decreases the intraoperative time needed to insert the tubes and minimises further trauma to the newly created punctal area. However, as this is a single case report, this conclusion should be substantiated with further larger studies or a randomised controlled study. Finally, we agree with previous reports ${ }^{5}$ that this method may spare a significant number of patients from undergoing CDCR with Lester Jones bypass tubes and does not prevent later intubation of such kind, if significant symptoms persist.

\section{Disclosures}

The authors report no financial or proprietary interest or conflicts of interest in this work.

\section{References}

1. Jones LT. Conjunctivodacryocystorhinostomy. Am J Ophthalmol. 1965;59:773-783.

2. Rosen N, Ashkenazi I, Rosner M. Patient dissatisfaction after functionally successful conjunctivodacryocystorhinostomy with Jones tube. Am J Ophthalmol. 1994;117(5):636-642.

3. Sekhar GC, Dortzbach RK, Gonnering RS, Lemke BN. Problems associated with conjunctivodacryocystorhinostomy. Am J Ophthalmol. 1991;112(5):502-506.

4. Khoubian JF, Kikkawa DO, Gonnering RS. Trephination and silicone stent intubation for the treatment of canalicular obstruction: effect of the level of obstruction. Ophthal Plast Reconstr Surg. 2006;22(4):248-252. 
5. Wearne MJ, Beigi B, Davis G, Rose GE. Retrograde intubation dacryocystorhinostomy for proximal and midcanalicular obstruction. Ophthalmology. 1999;106(12):2325-2328.
6. Jones LT. The cure of epiphora due to canalicular disorders, trauma and surgical failures on the lacrimal passages. Trans Am Acad Ophthalmol Otolaryngol. 1962;66:506-524.

\section{Publish your work in this journal}

Clinical Ophthalmology is an international, peer-reviewed journal covering all subspecialties within ophthalmology. Key topics include: Optometry; Visual science; Pharmacology and drug therapy in eye diseases; Basic Sciences; Primary and Secondary eye care; Patient Safety and Quality of Care Improvements. This journal is indexed on
PubMed Central and CAS, and is the official journal of The Society of Clinical Ophthalmology (SCO). The manuscript management system is completely online and includes a very quick and fair peer-review system, which is all easy to use. Visit http://www.dovepress.com/ testimonials.php to read real quotes from published authors. 